\title{
PREFACE
}

\section{A Note on Fieldwork}

My research on Malay rituals of healing began as a result of the kind of serendipity that seems to enhance the work of many anthropologists. When I arrived in Trengganu State, in 1975, prepared to study Malay childbirth and nutrition, I was unaware of the persistence of shamanism in the area. I expected to learn as much as I could about the cultural and ecological context in which Malay ideas and practices regarding food and reproduction are embedded. Understanding the Malay medical system as a totality, I believed, would be vital to the wider implications of my study. As I discovered, without the knowledge I gained from my association with Malay shamans, I might never have known even the basic "facts of life." Almost a year after I had begun to work as an apprentice to a traditional midwife and had assisted at numerous births, I attended a seance at which I was startled to hear one of the ritual specialists sing of the father's pregnancy. When I asked my midwifeteacher what that meant, she was equally startled. Imagine a grown, highly educated woman not knowing that a baby develops within its father's brain for forty days before its mother takes over! She pointed to her husband as an example, reminiscing about the time he carried their youngest child, and how he had craved sour foods during his pregnancy.

Had I not been privileged to attend shamanistic seances, I might never have understood the concept of the Inner Winds, a key to the traditional medical system. My understanding of the Winds came slowly, nurtured by my shaman-teachers and reinforced by conversations with Malay patients, friends, and neighbors. It was not until many years later, when I had read extensively in Western psychoanalytic and art historical literature, that I realized the important implications this concept had for my own society. 
My principal informants, Pak Long Awang bin Ali (a shaman) and Tok Daud bin Mat (his partner, or minduk), lived in my parish; I spoke to them frequently and taped their seances whenever and wherever they occurred, as part of their entourage. I also attended the seances of eight other practitioners of Main Peteri (pronounced approximately like the English "mine pet tree"), all of whom were born in Kelantan, although many had long been resident in Trengganu, and interviewed them extensively over a period of two years (1975-1977). I transcribed the tapes in the field and attempted a preliminary translation. I returned to Malaysia during 1982, on a grant from the Translations Program of the National Endowment for the Humanities, to check the accuracy of my previous transcriptions and translations of Main Peteri with the original performers and to study their meaning and symbolism further. All research and interviews were conducted in Malay local dialects, primarily Kelantanese, often intermingled with Trengganu expressions.

During the fifteen-odd years I have worked with these ritual dramas of healing, they have revealed the wit of their comedy and the beauty of their poetry, their validity as medicine as well as philosophy, and their profound understanding of the human condition. The unfolding process by which these texts have spoken to me has seemed at times like the unfolding that takes place during the shaman's divination, "Open the message, one fold within the gloomy darkness. Two folds shows a grayish haze. With three folds we can now see clearly." I hope that I have been able to reveal some of the clarity of the Malay shaman's vision of the universe.

\section{A Note on Translation}

Discussions of the Malay shaman's seance in the past were seriously hampered by the lack of texts transcribed from actual performances. Cuisinier, and earlier writers, had to rely on the dictation of informants after the fact. Skeat, who was present at part of a seance held for a sick man, remarked on the difficulty of following the language (1972[1900]:436-444). He was able to collect only part of an incantation that was dictated to him later. Cuisinier's generally excellent 


\section{Preface}

translation is excerpted from longer formal songs and incantations and omits the extensive colloquial dialogues between the spirits (speaking through the voice of the tok 'teri) and the master of the spirits (the minduk). Of the performances that Cuisinier describes, one was a special ceremony ordered by the Sultan of Kelantan for reasons of state (1936:97), and the other was staged for Cuisinier's benefit with no real patient or practical purpose (1936:39). Since Cuisinier based her analysis on these, rather than upon personally experienced rituals performed for health reasons, her comments about the Main Peteri, particularly in its function as a healing ceremony, are often wide of the mark.

Gimlette, who provided eight pages in English and a corresponding number in Malay of selections from Main Peteri songs, attests to the difficulty for non-native speakers of a language that he said was "made up of many elements: besides illiterate Malay it includes corrupt Arabic, broken Siamese, mutilated Javanese, debased Sanskrit, words from the spirit language" (1971[1915]:73). Cuisinier (1936) also notes the inclusion of "Sakai" [Orang Asli] words. Gimlette laments his shortcomings in understanding the language, but leaves one with no doubt as to the possibility of further scholarship's ability to unravel these problems. A more recent scholar, however, rather than improving on Gimlette's understanding, came to the conclusion that "there is little point in translating all of the incantations completely, as most are repetitious and full of mumbo-jumbo that means little in another language" (Shaw 1973:78).

Native speakers of Kelantanese Malay have little trouble understanding the language of the seance. Rather than finding it incomprehensible and repetitious, they find it endlessly diverting and meaningful.

Although seeking the "original form" of Malay texts appears to be a serious occupation of some Malay scholars, for example, Ismail Hussein (1974), it is fruitless to attempt to reconstruct "the original form" of the Main Peteri because of the emergent quality of each performance. Every seance is its own "original" whose plot and staging develop, to a large extent, out of particular circumstances, as well as owing a debt to specific performers and their audiences. I have attempted to show the great variety this form can attain by transcribing and translating three complete seances, presided over by six different ritual specialists. These 


\section{Preface}

were chosen from among the dozens of performances I witnessedperformances including one done for a boy suffering from a spirit attack that had been aimed at his father but struck the more vulnerable child; one for a new mother who refused to attend to her infant; one for a fat woman who annually took to her bed as a result of unrealized theatrical ambitions; one for a forestry official whose divorced wife periodically sent spirits to confuse his mind; one done in an attempt to evict a Chinese family from a Malay-owned house using the help of spirit familiars; and many rituals designed to encourage love or hate, or to return an errant spouse to his wife. Of the three performances I chose, the first ("A Stifled Talent") was held primarily to ease the virulent frustration that resulted from the thwarting of the patient's Inner Winds (a concept discussed in chapter 4); the second ("Seance for a Sick Shaman") combined exorcism with the strengthening of the sick shaman's professional Wind; the third ("Breaking Contracts with the Spirit World") was purely exorcistic, designed to rid the neighborhood of unsatisfied marauding spirits.

Readers of these texts should be aware that the Malay audiences at these performances are, for the most part, not intent on hearing every word, and for many reasons may miss some of the dialogue. Silence is not enjoined upon audiences. People come and go, there may be conversations carried on in low tones by members of the audience, and children are often present, sometimes making noise and often drifting off to sleep on floor mats in the area in which the ritual is taking place.

Transcriptions, based on tapes made by the author during performances, were done with the help of my field assistant, Yusof bin Hassan (a Trengganu Malay who had spent a good deal of time in Kelantan with his Kelantanese father), and the ritual specialists who presided over the seances. The greater part of the words, whether spoken or sung, could be heard clearly on the tapes, but problems arose when two performers spoke or sang simultaneously. Moreover, most elderly Malays (including many of the ritual specialists) have lost all or most of their teeth, which makes for diminished clarity of speech. The only section dictated to me after the fact was the tok 'teri's invocation while going into trance, which, at a performance, is recited during the singing of the minduk's Bestirring Song. On my tape, the minduk's song was a good 


\section{Preface}

deal louder than the shaman's invocation, making it impossible to hear the invocation clearly. In these instances, my readers have been presented with material that was not completely audible to the Malay audience.

Words that were unclear on the tapes were listened to time after time by the author, her field assistant, and the ritual specialists. Prof. P. L. Amin Sweeney also listened to and commented on the material, using copies of the original tapes. Where it was impossible to hear words or phrases even after extensive re-listening, I have so indicated. Although there may be questions about the accuracy of some isolated words, an alternate reading would not significantly change the meaning.

Inquiring about particular words during interviews with ritual specialists many years after the event proved unfruitful, since much of the dialogue is ad lib improvisation on underlying themes. Aside from the formulaic phrases that ornament the Main Peteri, bomoh can no more be expected to remember exactly what they said in the past (even when prompted by tape recordings) than can anyone who does not perform according to an unvarying script.

Like the Zuni storytellers described by Tedlock (1983), Main Peteri bomoh differ in the stresses, pitches, and intonations of their performance from ritual pair to ritual pair, as well as in the music they sing and the words they repeat. While these differences add to the impact of the performance, I believe that an attempt to reproduce them in the lengthy texts of the Main Peteri would detract from, rather than add to, the reader's understanding.

Although it is unreasonable to expect that a translation of ritual material could evoke a response in members of another culture similar to the one evoked by the original performance in its own setting (pace Nida), an adequate translation should make sense to the reader, convey the manner of the original, and be "natural and easy to read" (Nida 1964:162); it must not become "literary" where the original was not, introducing elegant variation where there was none in the text (Hymes 1981). The translator must surrender herself to the performance, to experience it as a participant, as well as an observer. It is only by learning to live another kind of life, and to speak another language, in the fullest sense, that a translator can hope to bring her readers any of the 


\section{Preface}

rich flavor of a performance she has experienced with all of her senses (cf. Asad 1986) as a participating member of the shaman's entourage and a member of the audience.

Scholars can read the original Malay transcriptions of these Main Peteri in my monograph, Main Peteri: Malay Shamanism (forthcoming). The original tapes are in the archives of Columbia University's Center for Ethnomusicology, Department of Music.

\section{The Structure of the Book}

The book is divided into two major parts, followed by an afterword, two appendixes, and a glossary. Part I, Malay Medicine, Malay Person, discusses the concepts and practices of traditional Malay healing. The initial chapter introduces the reader to Malay shamanism, first as I myself was introduced to it, and later through a review of changing Western attitudes toward the phenomenon. The second chapter relates the Malay humoral system, the cornerstone of both medical and cosmological theory, to medieval Islamic humoralism and to the beliefs of aborigines who live in the Malayan rain forest. The third chapter discusses "unusual illnesses," their etiology, and their relations to Malay concepts of the Self. Chapter 4 expands on the Inner Winds, a key component of the Malay Person, and compares Malay theories of personality development, creativity, and frustration with those of contemporary Western psychoanalysis. Chapter 5 considers the performance aspects of the shaman's seance, discussing its dramatic form, music, movement, and props. While Part I prepares the reader to understand the cultural context of the ritual dramas that follow, the epic sweep and poetic qualities of the Malay shaman's healing seances give them intrinsic value as oral literature and dramatic performance, beyond their anthropological interest. In Part II, Ritual Dramas of Healing, the anthropologist's voice fades further into the background and the ritual practitioners' voices come to the fore. The three chapters that make up Part II include translations of three complete performances of shamanic seances, extensively annotated. In these ritual dramas, the noble philosophy of the minduk's long introductory song and the lyric beauty of the Bestirring Song that helps the shaman achieve trance alternate with passages of striking met- 


\section{Preface}

aphor and coarse humor. The brief Afterword, "Words and Meaning," an appreciation of the language of healing, concludes the book. Of particular interest are the appendices, including a transcription of some of the music of the Main Peteri (courtesy of Marina Roseman), and a lengthy interview with a shaman. The anthropologist confines herself here to short questions for the shaman, and interpolated comments to the reader. The shaman himself is the central figure-his intelligence, understanding, and verve for his profession flow from his mouth with the force of a waterfall. 